\title{
Impaired odor recognition memory in patients with hippocampal lesions
}

\author{
Daniel A. Levy, ${ }^{1,2}$ Ramona O. Hopkins, ${ }^{5,6}$ and Larry R. Squire ${ }^{1,2,3,4,7}$ \\ ${ }^{1}$ Veterans Affairs Healthcare System, San Diego, California 92161, USA; Departments of ${ }^{2}$ Psychiatry, ${ }^{3}$ Neurosciences, and \\ ${ }^{4}$ Psychology, University of California, San Diego, California 92093, USA; ${ }^{5}$ Brigham Young University, Provo, Utah 84602, USA; \\ ${ }^{6}$ LDS Hospital, Salt Lake City, Utah 84143, USA
}

\begin{abstract}
In humans, impaired recognition memory following lesions thought to be limited to the hippocampal region has been demonstrated for a wide variety of tasks. However, the importance of the human hippocampus for olfactory recognition memory has scarcely been explored. We evaluated the ability of memory-impaired patients with damage thought to be limited to the hippocampal region to recognize a list of odors. The patients were significantly impaired after a retention delay of $1 \mathrm{~h}$. Olfactory sensitivity was intact. This finding is in agreement with earlier reports that rats with hippocampal lesions exhibited memory impairment on an odor delayed nonmatching to sample task (after $30 \mathrm{~min}$ and $1 \mathrm{~h}$ ) and that patients with damage thought to be limited to the hippocampal region were impaired on an odor span memory task. Olfactory recognition memory, similar to recognition memory in other sensory modalities, depends on the integrity of the hippocampal region.
\end{abstract}

Recognition memory refers to the ability to identify a previously encountered stimulus as familiar. In humans, monkeys, and rats, recognition memory depends on the integrity of the hippocampal region (the hippocampus proper, the dentate gyrus, and the subicular complex) (for review, see Squire et al. 2004). In humans, impaired recognition memory following lesions thought to be limited to the hippocampal region has been demonstrated for verbal and nonverbal material (Reed and Squire 1997) as well as for nonsense sounds (Squire et al. 2001) (For the view that some aspects of recognition performance are spared following hippocampal lesions, see Brown and Aggleton, 2001; Yonelinas et al. 2002; but see Manns et al. 2003, Wixted and Squire 2004).

The importance of the human hippocampus for olfactory recognition memory has scarcely been explored. In one recent study, patients with damage thought to be limited to the hippocampal region were impaired at both visual and olfactory memory span tasks modeled after tasks used in rats (Levy et al. 2003). Although these span tasks do require recognition memory, the retention delay is confounded with span length, and the same odor can be presented many times during the course of testing. Accordingly, it is difficult to relate findings from memory span tasks to findings from more conventional tasks of recognition memory in which stimuli are studied and then tested after fixed retention delays. To ask how hippocampal lesions affect conventional olfactory recognition memory in humans, we have evaluated the ability of memory-impaired patients and controls to recognize a list of odors after a delay of $1 \mathrm{~h}$.

The five amnesic patients (four men and one woman) who participated were included on the basis of evidence that they had bilateral damage limited primarily to the hippocampal region (CA fields, dentate gyrus, and subicular complex) (Table 1). All the patients had moderately severe memory impairment. Their average scores for copy and delayed (12 min) reproduction of the Rey-Osterrieth figure (maximum score $=36$; Osterrieth, 1944) were 28.8 and 2.6, respectively (controls $=30.3$ and 20.6) (Squire et al. 1989). Immediate (12 min) and delayed recall of a short

\section{${ }^{7}$ Corresponding author.}

E-mail Isquire@ucsd.edu; fax (858) 552-7457.

Article published online ahead of print. Article and publication date are at http://www.learnmem.org/cgi/doi/10.1101//m.82504. prose passage (Gilbert et al. 1968) averaged 4.6 and 0.4 segments, respectively ( 15 controls $=8.3$ and 7.1).

Patients A.B. and J.R.W. became amnesic after an anoxic episode associated with cardiac arrest (in 1976 for A.B. and 1990 for J.R.W.). G.W. and R.S. became amnesic following a drug overdose and associated respiratory failure (in 2001 for G.W. and 1998 for R.S.). L.J. became amnesic in 1988 during a 6-mo period with no known precipitating event. Her memory impairment has remained stable since that time.

For four of the five patients, estimates of the extent of medial temporal lobe damage were obtained from magnetic resonance imaging (MRI). Imaging was done in a $1.5 \mathrm{~T}$ clinical scanner (for the MRI scans for these patients, see Manns et al. 2003). The volume of the full anterior-posterior length of the hippocampus and the volume of the parahippocampal gyrus were measured by using criteria based on histological analysis of healthy brains (Amaral and Insausti 1990; Insausti et al. 1998).

Volumes were normalized by intracranial volume (ICV) to correct for between-subject variability in brain size (Gold and Squire 2004). Relative to age and gender-matched healthy controls (19 males and 11 females), L.J., R.S., G.W., and J.R.W. have an average bilateral reduction in hippocampal size of $46 \%, 33 \%$, $48 \%$, and $44 \%$, respectively. The parahippocampal gyrus was relatively unaffected (mean reduction $=3 \%$, range from $12 \%$ smaller to $8 \%$ larger). None of the patients had focal lesions in the entorhinal cortex or significant reductions in its volume (mean reduction $=12 \%$ ). The fifth patient (A.B.) is unable to participate in MRI studies but is thought to have hippocampal damage on the basis of etiology (anoxia) and a neurologic examination indicating well-circumscribed amnesia. In addition, highresolution computed tomography (CT) images obtained in 2001 were consistent with restricted damage to the hippocampal region (Schmolck et al. 2002). Sixteen healthy volunteers (12 men and four women) were also tested. They averaged 54.6 years of age and 13.8 years of education.

The stimuli consisted of 48 common foods, condiments, fragrances, and household items (e.g., garlic powder, almond extract, patchouli oil, shoe polish, machine oil), all of which had a distinctive odor. These 48 odors were used to construct two tests. For each test, 12 odors were presented for study, and 24 odors 
Table 1. Characteristics of amnesic patients

\begin{tabular}{lcccccccc}
\hline & & & & \multicolumn{5}{c}{ WMS-R } \\
\cline { 7 - 10 } Patient & $\begin{array}{c}\text { Age } \\
\mathbf{( y \mathbf { r } )}\end{array}$ & $\begin{array}{c}\text { Education } \\
\mathbf{( y \mathbf { r } )}\end{array}$ & $\begin{array}{c}\text { WAIS-III } \\
\text { IQ }\end{array}$ & Attention & Verbal & Visual & General & Delay \\
\hline J.R.W. & 40 & 12 & 90 & 87 & 65 & 95 & 70 & $<50$ \\
G.W. & 44 & 12 & 108 & 105 & 67 & 86 & 70 & $<50$ \\
R.S. & 47 & 12 & 99 & 99 & 85 & 81 & 82 & $<50$ \\
L.J. & 66 & 12 & 101 & 105 & 83 & 60 & 69 & $<50$ \\
A.B. & 66 & 20 & 107 & 87 & 62 & 72 & 54 & $<50$ \\
\hline
\end{tabular}

The Wechsler Adult Intelligence Scale-III (WAIS-III) and the Wechsler Memory Scale-Revised (WMS-R) yield mean scores of 100 in the normal population with a standard deviation of 15. The WMS-R does not provide numerical scores for individuals who score $<50$. IQ scores for J.R.W. and R.S. are from the Wechsler Adult Intelligence Scale-Revised.

were presented at test (12 studied odors and 12 foils). Which odors were studied and which odors were foils in each recognition test were counterbalanced across participants. Stimuli were presented in opaque vials $(9.8 \mathrm{~cm}$ tall), and no visual cues were available to participants at any time during testing.

The set of 12 odors was presented for study one at a time, and participants were instructed to sample each odor and decide how much they liked it on a scale of one (dislike very much) to five (like very much). Participants typically took one or two whiffs from each vial. The order of presentation of odors was randomized for each participant, and an interval of $\sim 10$ sec separated the presentation of each odor. After a pause of $\sim 30 \mathrm{sec}$, all 12 odors were then presented again in exactly the same way. Then, following the retention delay of $1 \mathrm{~h}$, which was filled with other activities, participants were once again presented the studied odors, now randomly interspersed among an equal number of foils. Participants were given each vial and asked to sample its contents and to indicate whether or not the odor had been presented previously. Again, participants typically took one or two whiffs from each vial. This test was given twice on two separate occasions (median interval $=20 \mathrm{~d}$ ), using the two different sets of odors.

Figure 1 shows the percentage correct and discrimination accuracy $\left(d^{\prime}\right)$ scores for the average of the two 1-h tests. After a 1 -h retention delay, the patients performed more poorly than did the controls (percentage correct: $67.0 \pm 1.3 \%$ versus $75.4 \pm 1.7 \%, t[19]=2.63, P<0.02 ; \mathrm{d}^{\prime}$ scores: $1.13 \pm 0.09$ versus $1.55 \pm 0.11, t[19]=2.00, P=0.06)$. Thus, recognition memory performance of the patients was impaired after $1 \mathrm{~h}$.

Abnormal olfactory sensitivity cannot account for impaired olfactory recognition memory. First, the liking ratings that were assigned to the odors when they were presented for study were nearly identical for the patients and the controls (mean for two presentations in each of two tests $=3.2$ and 3.0, respectively; $t$ $[19]=1.58, p>0.10$ ). Second, the five patients and 12 of the 16
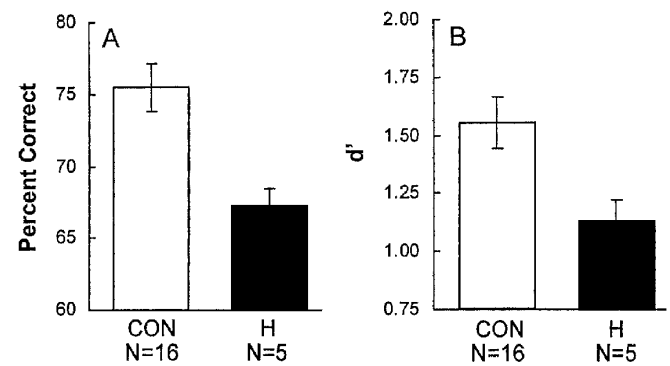

Figure 1. Percentage correct $(A)$ and discrimination accuracy $(B)\left(d^{\prime}\right)$ scores for patients with damage thought to be limited to the hippocampal region $(\mathrm{H})$ and matched controls (CON). Odor recognition memory was tested after a retention delay of $1 \mathrm{~h}$. Brackets show standard error of the mean. controls were given a test of olfactory threshold (Murphy et al. 1990; also see Levy et al. 2003). Briefly, ten 60 -mL solutions of $n$ butyl alcohol in deionized water (beginning with a $4.0 \%$ solution) were prepared in $250-\mathrm{mL}$ squeezable polyethylene bottles. Each successive solution was one-third the concentration of the preceding dilution. On each test trial, a bottle containing odorant and a second bottle of deionized water (no smell) were presented one at a time, beginning with the most dilute solution. Participants sampled from each pair of bottles with a single nostril and indicated which bottle contained the odorant (45-sec interval between samplings). Which nostril was tested first and the left/right presentation of the bottles were random across participants. After a correct choice, the same pair of bottles was presented again, up to a minimum of five correct trials. After an error, the next highest concentration of butanol was presented. Threshold was defined as the most dilute concentration at which five consecutive correct choices were made (nine indicates most dilute; zero, least dilute).

On this nine-point scale, the patients obtained mean thresholds of $6.2 \pm 0.6$ and $7.0 \pm 0.5$ (for the right and left nostrils, respectively), and the controls obtained corresponding thresholds of $6.9 \pm 0.3$ and $7.0 \pm 0.3$ (for patients versus controls, all $p>0.2$ ). Thus the patients had normal olfactory thresholds, and their judgments about the odors were similar to those of the controls.

These findings provide additional evidence for the multimodal nature of human memory impairment and provide what appears to be the first evidence for an impairment in olfactory recognition following lesions thought to be limited to the hippocampus in humans. Olfactory recognition was impaired in epileptic patients who had undergone unilateral temporal lobe resection. However, the removals in those patients involved not just the hippocampal region but also adjacent cortex in the parahippocampal gyrus, as well as the piriform cortex and the amygdala (Dade et al. 2002). Our results are also in agreement with the finding that rats with hippocampal lesions were impaired at olfactory recognition when the retention delay was either $30 \mathrm{~min}$ or $1 \mathrm{~h}$ (Dudchenko et al. 2000). Interestingly, in this and other earlier work with rats (Sutherland and McDonald 1990), olfactory recognition impairments were not observed after hippocampal lesions at shorter retention delays ( $\leq 15 \mathrm{~min})$.

To ask whether this finding holds only for rats or whether patients with hippocampal lesions might also exhibit good olfactory recognition at retention delays of only a few minutes, we gave our five patients and 16 controls (mean $=52.5$ years old; nine of these also participated in the main 1-h study) a test of olfactory recognition with a 5-min retention delay (study 10 odors, test with 10 studied odors and 10 foils). In other respects, the procedure was identical to the procedure used for the 1-h retention test described here. The patients and controls performed similarly (percentage correct: $71.0 \pm 5.6 \%$ versus $75.9 \pm 2.8 \%$; d' scores: $1.29 \pm 0.3$ versus $1.53 \pm 0.2 ; p>0.4$ ). These findings suggest that in humans, as well as in rodents, impaired olfactory recognition following hippocampal lesions may be apparent only after retention delays of many minutes. However, this conclusion must remain tentative in the absence of additional studies that assess olfactory recognition memory after multiple retention intervals and under identical conditions at each retention interval. 
It is of interest that in the study phase of the present experiment some participants spontaneously offered verbal labels for some of the odors (across all participants, labels were offered for $24 \%$ of the odors). The question therefore arises whether subsequent recognition performance might have depended importantly on remembering these verbal labels. Three observations bear on this issue. First, there was no indication that participants intentionally and regularly used labels (covertly or overtly) as an aid to remembering the odors. Second, in earlier studies, access to verbal labels at the time of study did not affect subsequent odor recognition performance (Engen and Ross 1973; AyabeKanamura et al. 1997). Although verbal elaboration about odors at the time of study can sometimes facilitate subsequent recognition (Lyman and McDaniel 1990), it is thought that odors are typically perceived as unitary items without a strong verbal link. That is, the association between odors and their verbal labels is ordinarily rather weak (Engen 1987; Lyman and McDaniel 1990). Third, in an earlier study involving the same odors (Levy et al. 2003), the olfactory memory span attained by controls (7.9) was about the same as the memory span for difficult-to-verbalize designs (8.6) and much less than the memory span for line drawings of nameable objects (21.1). Thus, although participants in the present study did sometimes volunteer a verbal label for an odor during the study phase, there is little reason to suppose that olfactory recognition memory performance was supported substantially by verbal mediation.

In summary, patients with lesions thought to be limited to the hippocampal region exhibited impaired olfactory recognition memory. Olfactory recognition memory, similar to recognition memory in other sensory modalities, depends on the integrity of the hippocampal region.

\section{Acknowledgments}

This work was supported by the Medical Research Service of the Department of Veterans Affairs, National Institute of Mental Health grant 24600, National Institute of Aging grant AG05131 to the Alzheimer's Disease Research Center at University of California at San Diego, and the Metropolitan Life Foundation. We thank Dr. Claire Murphy for advice on olfactory testing and Dr. Nicola Broadbent, Jeffrey Gold, Jennifer Frascino, and Leah Swalley for assistance.

\section{References}

Amaral, D.G. and Insausti, R. 1990. The hippocampal formation. In The human nervous system (ed. G. Paxinos), pp. 711-755. Academic Press, San Diego, CA.

Ayabe-Kanamura, S., Kikuchi, T., and Saito, S. 1997. Effect of verbal cues on recognition memory and pleasantness evaluation of unfamiliar odors. Percept. Mot. Skills 85: 278-285.

Brown, M.W. and Aggleton, J.P. 2001. Recognition memory: What are the roles of the perirhinal cortex and hippocampus? Nat. Rev. Neurosci. 2: 51-61.

Dade, L.A., Zatorre, R.J., and Jones-Gotman, M. 2002. Olfactory learning: Convergent findings from lesion and brain imaging studies in humans. Brain 125: 86-101.

Dudchenko, P.A., Wood, E.R., and Eichenbaum, H. 2000. Neurotoxic hippocampal lesions have no effect on odor span and little effect on odor recognition memory but produce significant impairments on spatial span, recognition, and alternation. J. Neurosci. 20: 2964-2977.

Engen, T. 1987. Remembering odors and their names Am. Sci. 75: $497-503$.

Engen, T. and Ross, B.M. 1973. Long-term memory of odors with and without verbal descriptions. J. Exp. Psychol. 100: 221-227.

Gilbert, J.G., Levee, R.F., and Catalano, F.L. 1968. A preliminary report on a new memory scale. Percept. Mot. Skills 27: 277-278.

Gold, J.J. and Squire, L.R. 2004. Quantifying medial temporal lobe damage in memory-impaired patients. Hippocampus (in press).

Insausti, R., Juottonen, K., Soininen, H., Insausti, A.M., Partanen, K., Vainio, P., Laakso, M.P., and Pitkanen, A. 1998. MR volumetric analysis of the human entorhinal, perirhinal, and temporopolar cortices. Am. J. Neuroradiol. 19: 659-671.

Levy, D.A., Manns, J.R., Hopkins, R.O., Gold, J.J., Broadbent, N.J., and Squire, L.R. 2003. Impaired visual and odor recognition memory span in patients with hippocampal lesions. Learn. Mem. 10: 531-536.

Lyman, B.J. and McDaniel, M.A. 1990. Memory for odors and odor names: Modalities of elaboration and imagery. J. Exp. Psychol. Learn. Mem. Cognit. 16: 656-664.

Manns, J.R., Hopkins, R.O., Reed, J.M., Kitchener, E.G., and Squire, L.R. 2003. Recognition memory and the human hippocampus. Neuron 37: 171-180.

Murphy, C., Gilmore, M.M., Seery, C.S., Salmon, D.P., and Lasker, B.R. 1990. Olfactory thresholds are associated with degree of dementia in Alzheimer's disease. Neurobiol. Aging 11: 465-469.

Osterrieth, P.A. 1944. Le test de copie d'une figure complexe. Arch. Psychol. 30: 206-356.

Reed, J.M., and Squire, L.R. 1997. Impaired recognition memory in patients with lesions limited to the hippocampal formation. Behav. Neurosci. 111: 667-675.

Schmolck, H., Kensinger, E.A., Corkin, S., and Squire, L.R. 2002. Semantic knowledge in patient H.M. and other patients with bilateral medial and lateral temporal lobe lesions. Hippocampus 12: $520-533$.

Squire, L.R., Amaral, D.G., Zola-Morgan, S., Kritchevsky, M., and Press, G. 1989. Description of brain injury in amnesic patient N.A. based on magnetic resonance imaging. Exp. Neurol. 105: 25-35.

Squire, L.R., Schmolck, H., and Stark, S. 2001. Impaired auditory recognition memory in amnesic patients with medial temporal lobe lesions. Learn. Mem. 8: 252-256.

Squire, L.R., Stark, C.E.L., and Clark, R.E. 2004. The medial temporal lobe. Annu. Rev. Neurosci. 27: 279-306.

Sutherland, R.J. and McDonald, R.J. 1990. Hippocampus, amygdala, and memory deficits in rats. Behav. Brain Res. 37: 57-79.

Wixted, J. and Squire, L.R. 2004. Recall and recognition are equally impaired in patients with selective hippocampal damage. Cogn. Affect. Behav. Neurosci. 4: 58-66.

Yonelinas, A.P., Kroll, N.E., Quamme, J.R., Lazzara, M.M., Sauve, M.J., Widaman, K.F., and Knight, R.T. 2002. Effects of extensive temporal lobe damage or mild hypoxia on recollection and familiarity. Nat. Neurosci. 5: 1236-1241.

Received June 11, 2004; accepted in revised form September 21, 2004. 


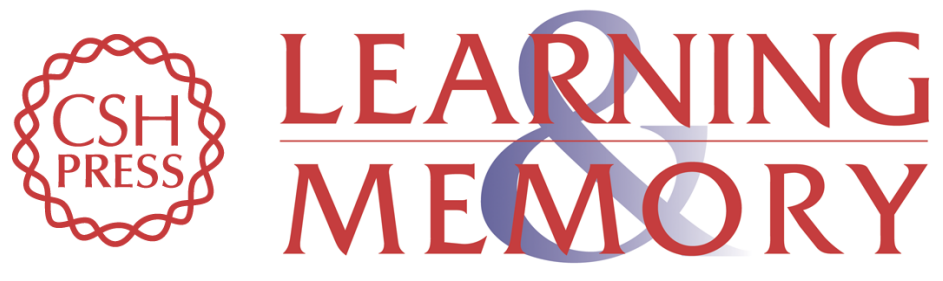

\title{
Impaired odor recognition memory in patients with hippocampal lesions
}

\author{
Daniel A. Levy, Ramona O. Hopkins and Larry R. Squire
}

Learn. Mem. 2004, 11:

Access the most recent version at doi:10.1101//m.82504

References This article cites 21 articles, 3 of which can be accessed free at:

http://learnmem.cshlp.org/content/11/6/794.full.html\#ref-list-1

License

Email Alerting Receive free email alerts when new articles cite this article - sign up in the box at the Service top right corner of the article or click here. 